DOI: 10.24287/1726-1708-2021-20-3-108-115

(c) 2021 ФГБУ «НМИЦ ДГОИ им. Дмитрия Рогачева»

Минздрава России

Поступила 29.03.2021

Принята к печати 25.06.2021

Контактная информация

Ахаладзе Дмитрий Гурамович, канд. мед. наук, руководитель группь торакоабдоминальной хирургии ФГБУ «НМИЦ ДГОИ им. Дмитрия Рогачева»

Минздрава России

Адрес: 117997, Москва,

ул. Саморы Машела, 1

E-mail: d.g.akhaladze@gmail.com

(C) 2021 by «D. Rogachev NMRCPHOl»

Received 29.03.2021 Accepted 25.06.2021 Dmitry G. Akhaladze cand. med. sci., head of thoracoabdominal surgery group, Dmitry Rogachev National Medical Research Center of Pediatric Hematology, Oncology and Immunology,

Ministry of Healthcare

of the Russian Federation

Address: 1 Samory Mashela St. Moscow 117997, Russia

E-mail: d.g.akhaladze@gmail.com
Тромбоз нижней полой вены и правого предсердия при эмбриональных опухолях у детей

\author{
Д.Г. Ахаладзе ${ }^{1}$, К.В. Шаталов², И.В. Арнаутова², Н.Н. Меркулов ${ }^{1}$, Д.Ю. Качанов ${ }^{1}$
} Г.Г. Заргинава ${ }^{2}$, А.А. Кривоносов ${ }^{1}$, Н.В. Мякова ${ }^{1}$

${ }^{1}$ ФГБУ «Национальный медицинский исследовательский центр детской гематологии, онкологии и иммунологии им. Дмитрия Рогачева» Минздрава России, Москва

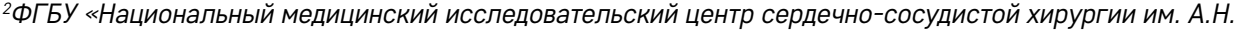
Бакулева» Минздрава России, Москва

Опухолевый тромбоз центрального венозного русла при эмбриональных опухолях у детей - редкое осложнение, требующее комплексного подхода в лечении, включающего полихимиотерапию и вмешательство многопрофильной команды, состоящей из хирургов-онкологов и кардиохирургов. В статье рассмотрено описание истории болезни пациента 9 месяцев с билатеральной нефробластомой и опухолевым тромбозом нижней полой вены и правого предсердия, а также представлен краткий обзор литературы. Родители пациента дали согласие на использование информации, в том числе фотографий ребенка, в научных исследованиях и публикациях.

Ключевые слова: опухолевый тромбоз нижней полой вены, нефробластома, дети, искусственное кровообращение, тромбоз правого предсердия

Ахаладзе Д.Г. и соавт. Вопросы гематологии/онкологии и иммунопатологии в педиатрии. 2021; 20 (3): 108-115. DOI: 10.24287/1726-1708-2021-20-3-108-115

\section{Inferior vena cava and right atrial thrombosis in children with embryonal tumors}

D.G. Akhaladzeㄹ, K.V. Shatalov², I.V. Arnautova ${ }^{2}$, N.N. Merkulov, D.Yu. Kachanov ${ }^{1}$, G.G. Zarginava ${ }^{2}$, A.A. Krivonosov ${ }^{1}$, N.V. Miakova

${ }^{1}$ Dmitry Rogachev National Medical Research Center of Pediatric Hematology, Oncology and Immunology, Ministry of Healthcare of the Russian Federation, Moscow

${ }^{2}$ A.N. Bakulev National Medical Research Center of Cardiovascular Surgery, Ministry of Healthcare of the Russian Federation, Moscow

Tumor thrombosis of the central venous system in children with embryonal tumors is a rare complication, requiring a comprehensive treatment approach, with chemotherapy and the intervention of a multidisciplinary team of oncologists and cardiac surgeons. The article describes the medical history of a 9-month-old patient with bilateral nephroblastoma and tumor thrombosis of inferior vena cava and right atrium, as well as provides a brief review of the literature. The patient's parents gave their consent to the use of their child's data, including photographs, for research purposes and in publications.

Key words: inferior vena cava tumor thrombosis, nephroblastoma, children, cardiac bypass, right atrial thrombosis

Akhaladze D.G., et al. Pediatric Hematology/Oncology and Immunopathology. 2021; 20 (3): 108-115

DOI: 10.24287/1726-1708-2021-20-3-108-115
O пухолевый тромбоз различных отделов венозного русла является редким, но грозным осложнением при некоторых солидных опухолях у детей. В мировой литературе находят отражение единичные наблюдения тромбозов нижней полой вены (НПВ) при ряде злокачественных новообразований детского возраста: опухоли печени [1, 2], нейробластома забрюшинной локализации [2-6], опухоли почки, преимущественно нефробластома $[7,8]$, опухоли органов женской репродуктивной системы [2, 9], также описаны тромбозы НПВ неопухолевого генеза при нарушениях системы свертывания и септических состояниях $[10,11]$. Опухолевый тромбоз при нефробластоме встречается примерно в $4-10 \%$ случаев. Из этого числа в $20-35 \%$ случаев тромбоз локализован в почечной вене и у $1-6 \%$ пациентов распространяется до правого предсердия [12].

Лечение опухолевых тромбозов является сложной задачей, требующей подготовки и детального планирования хирургической тактики. Внутрипредсердные тромбы относятся к наиболее редким видам тромбозов и требуют высокотехнологичной хирургической помощи, подразумевающей взаимодействие хирургов различных специальностей, а также онкологов и лучевых диагностов $[13,14]$.

Целью настоящей публикации является описание собственного клинического наблюдения, а также представление обзора литературы, отра- 
жающего опыт лечения детей с преимущественно эмбриональными опухолями, осложненными распространенным тромбозом НПВ.

Родители пациента дали согласие на использование информации, в том числе фотографий ребенка, в научных исследованиях и публикациях.

\section{Клинический случай}

Мальчик, 9 месяцев, впервые был обследован в стационаре по месту жительства в связи с жалобами на водянку яичек. По данным мультиспиральной компьютерной томографии выявлено билатеральное опухолевое поражение почек. Справа размер опухоли составил $110 \times 100 \times 127$ мм, объем 667 мл, слева $17 \times 16 \times 14$ мМ, объем 1,9 мл. Просвет НПВ был тотально выполнен характерным для данного заболевания тромбом, распространяющимся в левую почечную и правую печеночную вены и выше, в правое предсердие (стадия IV по Ciancio [15]). Размер опухолевого тромба составил $80 \times 19 \times 20$ мм (рисунок 1). Очаговых новообразований легких и других локализаций при обследовании выявлено не было. Ввиду наличия распространенного опухолевого тромбоза, вызывающего вторичную легочную гипертензию и синдром Бадда-Киари, пациенту была назначена антикоагулянтная терапия низкомолекулярным гепарином в лечебной дозировке. С учетом двустороннего поражения почек и наиболее вероятного диагноза - нефробластома - была начата неоадъювантная химиотерапия в рамках протокола SIOP-RTSG 2016 [16] в режиме AVD (актиномицин D, винкристин, доксорубицин). Лечение ребенок переносил удовлетворительно, модификации доз не требовалось. После завершения 7 курсов полихимиотерапии через 2 мес от начала заболевания пациент был переведен в НМИЦ ДГОИ им. Дмитрия Рогачева для хирургического этапа лечения. При поступлении состояние ребенка было тяжелым за счет кахексии и выраженной опухолевой интоксикации, однако параметры гемодинамики оставались стабильными и не требовали медикаментозной коррекции, видимо, в связи с развитием коллатерального кровообращения.

По данным компьютерной томографрии после неоадъювантной химиотерапии и антикоагулянтной терапии размер опухолей правой и левой почек, а также размер и распространенность опухолевого тромба не изменились (рисунок 2). Таким образом, хирургическое вмешательство являлось единственно возможным вариантом лечения резистентного к химиотерапии новообразования. Учитывая высокую локализацию опухолевого тромба и билатеральное поражение почек, было решено провести операцию усилиями совместной бригады онкохирургов и кардиохиругов. После консилиума с кардиохирургами НМИЦ ССХ им. А.Н. Бакулева и подробного обсуждения технических особенностей оперативного вмешательства, характеристик опухолевого тромба по данным инструментальных исследований (отсутствие фрлотации и опасности эмболии) первым был запланирован абдоминальный этап операции в целях удаления правой почки и надпочечника. Планировалась также экстирпация НПВ, поскольку длительное существование ее полной обструкции позволило сформироваться коллатеральному кровообращению. Необходимость правосторонней гемигепатэктомии предстояло решить интраоперационно.

\section{Абдоминальный этап операции}

Пациент был переведен в НМИЦ ССХ им. А.Н. Бакулева, где после плановых подготовительных мероприятий был выполнен первый этап операции. При осуществлении доступа в брюшную полость обращала на себя внимание резко увеличенная в размере печень, плотной консистенции, синюшного цвета (следствие диагностированного ранее синдрома Бадда-Киари). Правая почка, замещенная опухолью, имела размер $120 \times 110$ мм и была мобилизована в едином блоке с правым надпочечником. При ревизии левой почки в верхнем полюсе определялось мягкотканное образование плотноэластической консистенции, размерами $18 \times 16$ мм. В результате опухолевого тромбоза НПВ на расстоянии 5 см проксимальнее конфлюенса подвздошных вен была резко расширена и имела диаметр не менее 4 см. После мобилизации правой почки была выделена на протяжении левая почечная вена, просвет которой на дистанции до 10 мм был выполнен опухолевым тромбом. При интраоперационном ультразвуковом исследовании было подтверждено распространение опухолевого тромба в просвет правой печеночной вены с частичным сохранением пристеночного кровотока.

Далее приступили к правосторонней гемигепатэктомии. При разделении рыхлой паракавальной клетчатки из медиальной полуокружности правой печеночной вены началось интенсивное кровотечение. В связи с продолжающимся кровотечением и невозможностью ушивания дефекта печеночной вены в условиях выраженного синдрома Бадда-Киари и его последствий выполнена тотальная сосудистая изоляция печени (пережата гепатодуоденальная связка, наложены турникеты на подпеченочный и поддиафрагмальный отделы НПВ). Паренхима печени разделена вдоль главной портальной фиссуры. После пересечения правых сосудов афферентного и эффферентного кровоснабжений и правого долевого печеночного протока выполнены правосторонняя гемигепатэктомия, сегментэктомия 1, пуск кровотока. Время тотальной сосудистой изоляции печени составило 44 мин. Кровоток в левой доле печени адекватный. 
Рисунок 1

Компьютерная томограмма до неоадъювантной химиотерапии: 1 - опухоль правой почки; 2 - опухолевый тромб в НПВ; 3 - опухолевый тромб в правом предсердии

Figure 1

A CT image before neoadjuvant chemotherapy: 1 - the tumor of the right kidney; 2 - the tumor thrombus in the inferior vena cava; 3 - the tumor thrombus in the right atrium

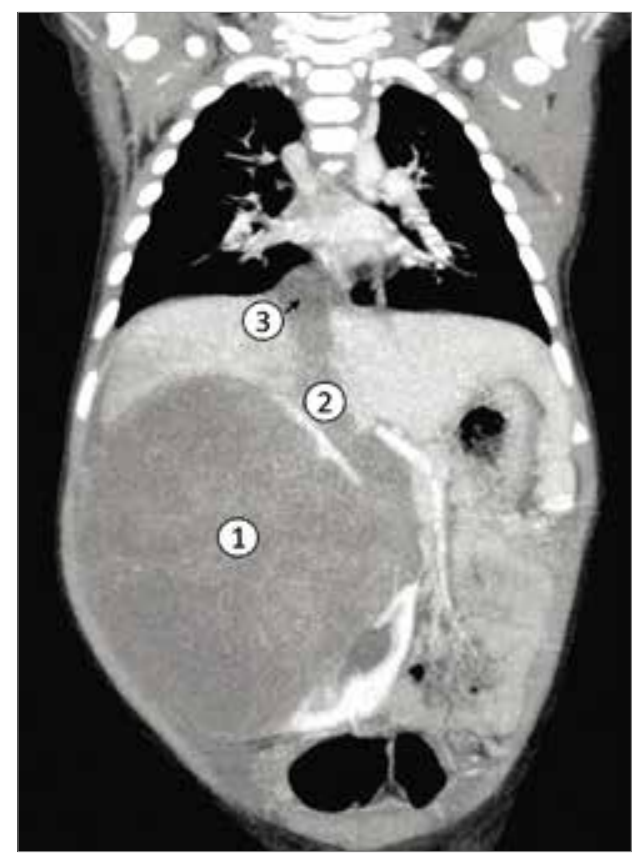

Рисунок 2

Компьютерная томограмма после неоадъювантной химиотерапии: 1 - опухолевый тромб в правой печеночной вене; 2 - опухолевый тромб в левой почечной вене; 3 - опухолевый тромб в НПВ; 4 - опухоль правой почки

Figure 2

A CT image after neoadjuvant chemotherapy: 1 - the tumor thrombus in the right hepatic vein; 2 - the tumor thrombus in the left renal vein; 3 - the tumor thrombus in the inferior vena cava; 4 - the tumor of the right kidney

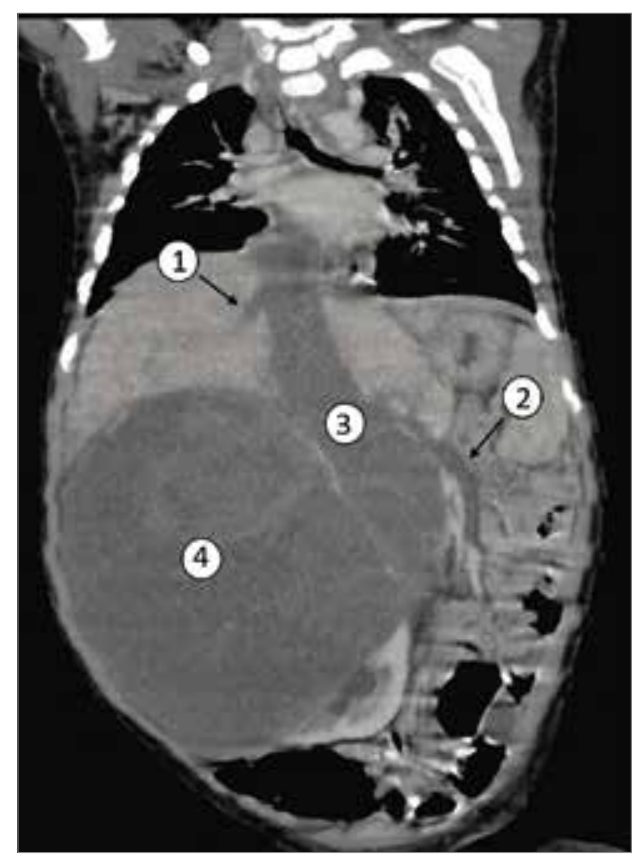

В связи с продолжающейся диффузной кровоточивостью и нестабильностью параметров гемодинамики было принято решение об удалении мобилизованного органокомплекса с забрюшинными лимфатическими узлами и завершение вмешательства. Интраоперационная кровопотеря составила 750 мл (79,8 мл/кг). Таким образом, на первом этапе были выполнены нефрадреналэктомия справа, правосторонняя гемигепатэктомия, сегментэктомия 1, экстирпация НПВ, забрюшинная лимфаденэктомия (рисунки 3, 4). Непрерывность НПВ не восстанавливалась в связи с адекватным оттоком от левой почки и нижних конечностей по сформированным венозным коллатералям. Резекция левой почки как этап комплексного лечения билатеральных нефробластом была запланирована после проведения дополнительных курсов химиотерапии по схеме AV (винкристин, дактиномицин) в целях соблюдения временных интервалов протокола.

\section{Кардиохирургический этап операции}

После стабилизации пациента и улучшения гемодинамических показателей на 3-и сутки после абдоминального этапа было принято решение о выполнении кардиохирургического вмешательства.

Была выполнена срединная стернотомия. Обнаружено, что сердце увеличено в размерах за счет правых отделов, и в полости правого предсердия определяется плотное опухолевидное образование, исходящее из устья НПВ. На фоне гипотермической перфузии с охлаждением тела больного до $32^{\circ} \mathrm{C}$ произведено вскрытие параллельно атриовентрикулярной борозде и визуализировано опухолевидное образование с гладкой поверхностью, плотной консистенции, исходящее из устья НПВ, интимно прилегающее к ее стенке (рисунок 5). Попытки энуклеации опухоли из НПВ были неэффективными, в связи с чем принято решение об удалении опухоли вместе с культей ранее отсеченной НПВ. Рассечен правый купол диафрагмы, удалена культя НПВ с опухолью с оставлением участка НПВ с дренирующими устьями левой и средней печеночных вен, из которых получен адекватный кровоток. С использованием ксенографта (из яремной вены быка) сформирован тоннель для оттока из левой и срединной печеночных вен в правое председие (рисунок 6). Пациент был согрет, сердечная деятельность с синусовым ритмом восстановилась самостоятельно. Продолжительность искусственного кровообращения составила 128 мин.

Заключение гистологического исследования удаленного органокомплекса: нефробластома, стромальный тип, гистологически группа промежуточного риска, локальная стадия III (витальный опухолевый тромб в крае НПВ). 
Рисунок 3

Макропрепарат, резецированный единым блоком: 1 - правая доля печени; 2 - НПВ; 3 - правая почка несущая опухоль, и правый надпочечник; 4 - S1 печени

Figure 3

A gross specimen resected en bloc: 1 - the right lobe of the liver; 2 - the inferior vena cava; 3 - the right kidney containing the tumor and the right adrenal gland; $4-\mathrm{S} 1$ of the liver

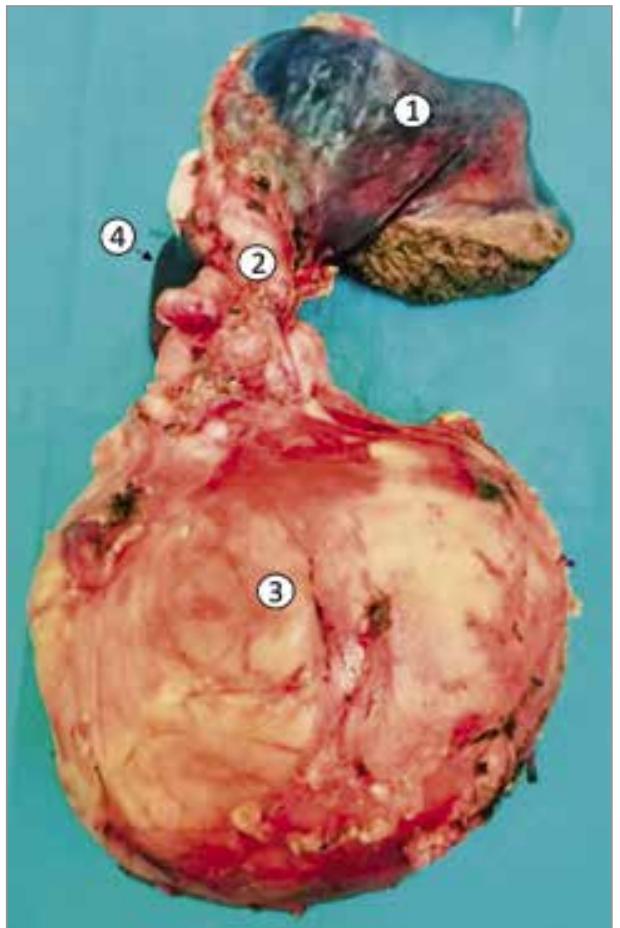

Рисунок 4

Вид операционного поля после удаления органокомплекса и забрюшинной лимфаденэктомии: 1 культя поддиафрагмального отдела НПВ; 2 - культя пузырного протока; 3 - культя правой почечной артерии; 4 - дистальная культя НПВ; 5 - культя левой почечной вены

Figure 4

An operating field after the resection of the block of organs and a retroperitoneal lymphadenectomy: the stump of the subdiaphragmatic portion of the inferior vena cava; 2 - the stump of the cystic duct; 3 - the stump of the right renal artery; 4 - the distal stump of the inferior vena cava; 5 - the stump of the left renal vein

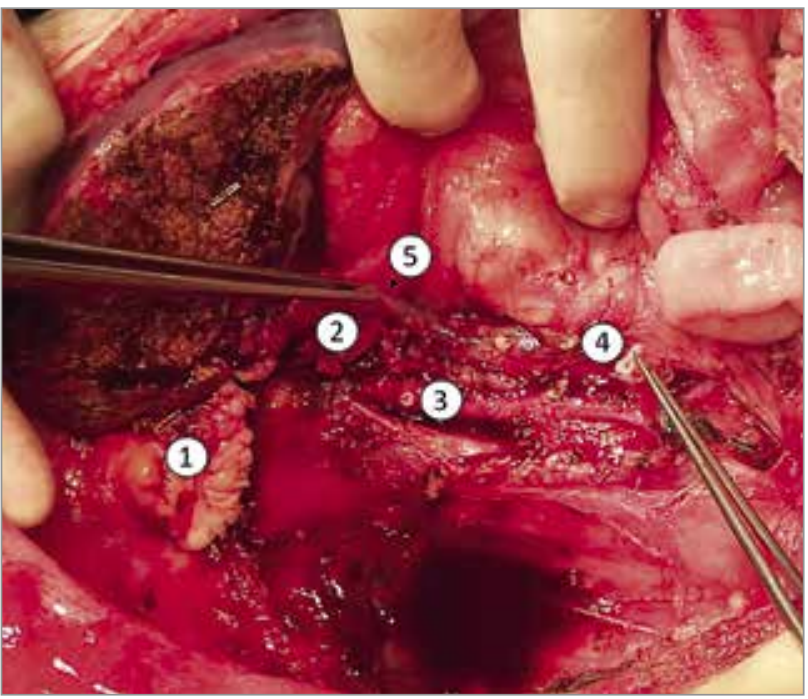

\section{Рисунок 5}

Опухолевый тромб в правом предсердии: 1 - опухолевый тромб; 2 - правое предсердие при атриотомии Figure 5

The tumor thrombus in the right atrium: 1 - the tumor thrombus; 2 - the right atrium during atriotomy

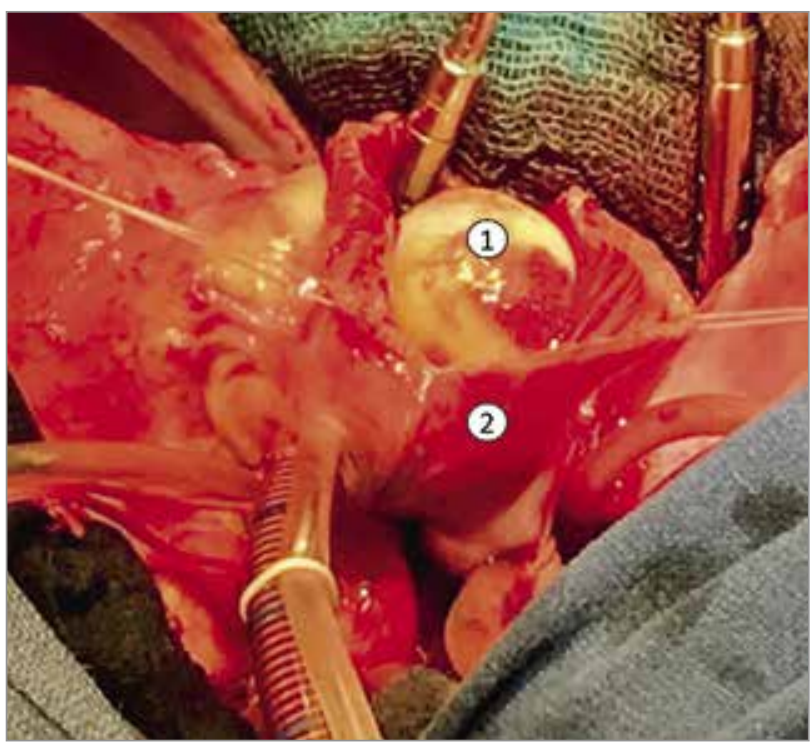

Рисунок 6

Пластика НПВ ксенографртом: 1 - правое предсердие после пластики; 2 - сформированный кондуит

Figure 6

A plastic repair of the inferior vena cava with a xenograft: 1 - the right atrium after the surgical repair; 2 - a newly formed conduit

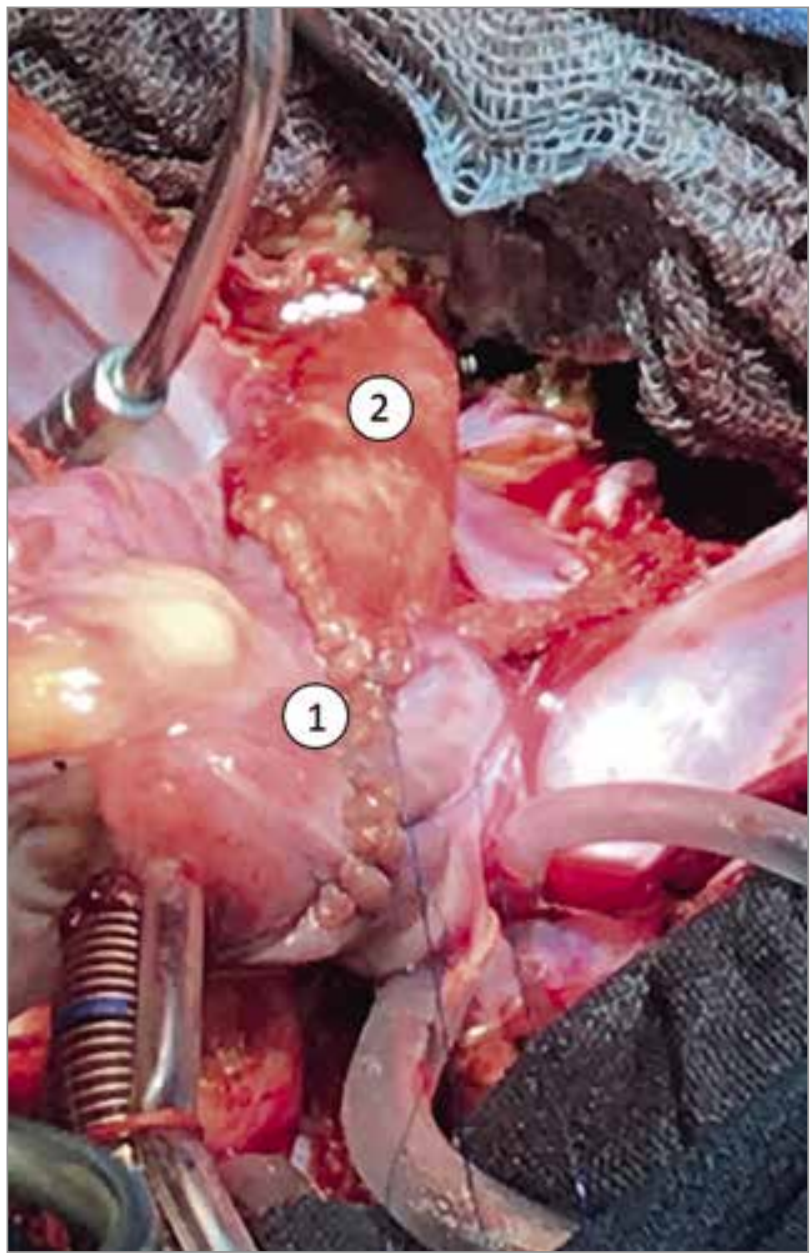


После стабилизации состояния в отделении реанимации и интенсивной терапии НМИЦ ССХ им. А.Н. Бакулева пациент был направлен в отделение реанимации и интенсивной терапии НМИЦ ДГОИ им. Дмитрия Рогачева. Ребенок был переведен на самостоятельное дыхание, параметры жизнедеятельности оставались стабильными. Учитывая витальную опухоль по данным гистологического исследования, на 11-е сутки после операции согласно протоколу SIOP-RTSG 2016 была начата адъювантная химиотерапия (винкристин). К сожалению, к 28-м суткам состояние ребенка ухудшилось за счет септических осложнений, и на 30-е сутки после последнего хирургического вмешательства пациент умер из-за прогрессии полиорганной недостаточности.

\section{Обсуждение и обзор литературы}

Описанное нами наблюдение иллюстрирует максимальный объем вмешательства при нефробластоме, включающий в том числе резекцию печени. Несмотря на то, что опухолевый тромбоз осложняет течение у детей с нефробластомой с частотой до $10 \%$ [12], его распространение в НПВ выше устьев печеночных вен, в том числе распространение в их просвет и на камеры сердца, достаточно редкое явление [17], вызывающее ряд вопросов. Среди них: роль неоадъювантной химиотерапии с точки зрения сокращения размеров опухолевого тромба и влияние полученного результата на стратегию хирургического этапа лечения, место применения искусственного кровообращения при распространении тромба выше диафрагмы, тактика относительно пластики НПВ и используемые для этого материалы.

Впервые случай опухолевого тромбоза НПВ с вовлечением правых отделов сердца при нефробластоме у ребенка описал $\mathrm{G}$. Anselmi при аутопсии в 1970-е годы [18]. С тех пор были сформированы подходы к лечению данного состояния. Тактика лечения детей с опухолью Вильмса, осложненной тромбозом НПВ, в Европейском (SIOP) и Американском (COG - Children's Oncology Group) протоколах схожи [16, 19]. Дети получают неоадъювантную химиотерапию, за которой следует хирургическое вмешательство. В 1970-е годы J. Wagget и С. Koop впервые использовали предоперационную химиотерапию для уменьшения размеров опухолевых тромбов у детей с нефробластомой, используя актиномицин D и винкристин [20]. R. Shamberger и соавт. отметили уменьшение опухолевого тромба у 39 (80\%) из 49 пациентов с опухолью Вильмса после 8 курсов полихимиотерапии, что подтвердило ее преимущества [20]. G. Hadley и соавт. показали, что после неоадъювантной химиотерапии у $30 \%$ детей с локализацией тромба в предсердии имело место его сокращение, а тромбэкстракция из НПВ не потребовала искус- ственного кровообращения [21, 22]. Принимая во внимание уверенность в необходимости радикального удаления опухолевого тромба, которая объединяет подавляющее большинство работ, а также техническую сложность таких операций, преимущества предоперационного химиотерапевтического лечения стали очевидными. Напротив, встречаются публикации, где уменьшение опухолевого тромба надпеченочной локализации в ответ на лекарственное лечение описано не у всех анализируемых пациентов, а лишь в 10-13\% наблюдений [21, 23, 24]. Так, M. Elayadi и соавт. связывают такие результаты с наличием «кровяного» компонента в опухолевом тромбе, на размеры которого не влияет применение химиотерапевтических агентов. Даже при отсутствии сокращения объема опухолевого тромба, неоадъювантная химиотерапия уменьшает его толщину и степень инвазии в сосудистую стенку, что ключевым образом может влиять на хирургическую стратегию. Тем не менее излишне длительная химиотерапия, напротив, может способствовать адгезии опухолевого тромба к эндотелию, затрудняя выполнение хирургического вмешательства [25].

Следует отметить, что несмотря на то, что наличие опухолевого тромбоза НПВ общепризнанно рассматривается как показание к проведению неоадъювантной химиотерапии, вопрос о ее длительности и количестве используемых препаратов остается открытым [26]. L. Morris и соавт. проанализировали влияние длительности предоперационной химиотерапии на частоту регресса опухолевого тромба. В первой части исследования изучались описанные в англоязычной литературе случаи за период 1996-2013 гг. ( $n=498$, из них с вовлечением правого предсердия 136 (27\%). Было показано, что продление предоперационной химиотерапии более 6 нед по сравнению со стандартным курсом (4-6 нед) не влияло на частоту регресса опухолевого тромба, полноту резекции и необходимость выполнения кавотомии. К аналогичным выводам авторы пришли при анализе медицинских данных 166 пациентов с опухолевым тромбозом, включенных в протокол SIOP WT 2001, получавших 4 нед неоадъювантой химиотерапии по схеме AV или 6 нед по схеме AVD. Интересными в контексте описываемого случая явились данные о том, что гистологический тип опухоли влиял на частоту регресса опухолевого тромба, при этом сокращение размеров тромба у пациентов со стромальным вариантом нефробластомы было выявлено лишь в $17 \%$ случаев. В связи с этим в протоколе SIOP-RTSG 2016 при наличии опухолевого тромбоза НПВ у пациентов с локализованными формами нефробластомы рекомендовано проведение стандартной предоперационной химиотерапии по схеме $\mathrm{AV}$ в течение 4 нед [26]. 
В представленном нами наблюдении неоадъювантная химиотерапия по схеме AVD не оказала влияния на размер и распространенность опухолевого тромба, равно как и на степень инвазии сосудистой стенки, что вынудило выполнить экстирпацию сосуда на всем протяжении. Пристеночный кровоток был сохранен лишь на ограниченном участке - в зоне впадения левой и срединной печеночных вен. Объяснением отсутствия значимого сокращения опухоли на фоне проведенного лечения явились результаты планового гистологического исследования, свидетельствующие о стромальном варианте нефробластомы.

S.S. Qureshi и соавт. поставили перед собой задачу оценить характеристики тромбов НПВ и их влияние на выживаемость [27]. Исследование включало 43 пациента с нефробластомой в возрасте от 1,6 до 13,5 года с опухолевым тромбозом НПВ. у $26 \%$ детей опухолевый тромб имел внутрипредсердную локализацию. В $63 \%$ случаев на фоне неоадъювантной химиотерапии опухолевый тромб в предсердии регрессировал, что позволяло избежать тромбоэкстракции в условиях искусственного кровообращения. Другим 7 пациентам для тромбоэкстракции искусственное кровообращение все же потребовалось. Общая и безрецидивная 5-летняя выживаемости всех пациентов с опухолью Вильмса составили $82 \%$ и $81 \%$ соответственно. Авторы пришли к выводу, что наличие опухолевого тромба, его интраоперационная фррагментация (у 27 (72,9\%) пациентов) не влияет на онкологический прогноз, но распространение тромба на правые камеры сердца ассоциировано с более высокой частотой хирургических осложнений. Ранее считали, что использование искусственного кровообращения у детей связано с риском переохлаждения, большей кровопотерей и развитием коагулопатии [28], но в литературе находит отражение и противоположное мнение [29]. Работа S.S. Qureshi и соавт. примечательна также тем, что в ней упомянута фрагментация опухолевого тромба и обсуждено отсутствие влияния на прогноз этого обстоятельства. Остается предположить, что авторы уповают на эффект адъювантной химиотерапии и, вероятно, лучевой терапии. Такую тактику оправдывает описание успешного опыта лечения девочки 2,5 года с нефробластомой правой почки с прорастанием опухолевого тромба в правый желудочек и инвазию в печеночные вены. После неоадъювантной химиотерапии ребенку была выполнена нефрэктомия, затем в условиях искусственного кровообращения - тромбоэкстракция из правого предсердия и правого желудочка. Инвазия тромба в печеночные вены не позволила выполнить радикальную резекцию. Гистологически верифицирована нефробластома смешанного гистологического типа, промежуточная группа риска. Ребенок получил адъювантную химиотерапию и лучевую терапию в дозе 25,2 Гр с удовлетворительным результатом [30].

У описанного нами пациента использование аппарата искусственного кровообращения было обязательным, а решение о выполнении правосторонней гемигепатэктомии было принято в целях повышения радикальности операции и удаления любых макроскопически определяемых проявлений болезни, особенно учитывая отсутствие эффекта от предоперационной химиотерапии и невозможность рассчитывать на эффект предстоящих химио- и лучевой терапии. В то же время в сложившихся интраоперационных условиях удалить опухоль единым блоком с внутрипредсердным компонентом тромба не представлялось возможным, и культя НПВ под диафрагмой была оставлена до удаления на кардиохирургическом этапе операции (локальная стадия III подтверждена результатом гистологического исследования). Стромальный морфологический тип нефробластомы, невзирая на локальную стадию III, позволил бы рассчитывать на удовлетворительный онкологический результат после завершения лечения по протоколу SIOP-RTSG 2016. К сожалению, инфекционные осложнения, развившиеся после химиотерапии, локализовать не удалось, и пациент умер от сепсиса и полиорганной недостаточности.

У подобных пациентов помимо применения искусственного кровообращения отдельного внимания заслуживают такие технические особенности операций, как выбор оптимального доступа и тактика в отношении протезирования/пластики магистрального сосуда. При удалении небольших нефиксированных тромбов в предсердии в литературе описаны абдоминальный доступ и френотомия с последующей тромбоэкстракцией. При наличии технической возможности тромб низводят ниже диафрагмы и «вывихивают» из просвета сосуда. У описанного в настоящей статье пациента такой доступ был невыполним в связи с облитерацией и инвазией тромба в стенку НПВ. Инвазия тромба в НПВ ставит вопрос о частичной или полной резекции сосуда. S. Psutka демонстрирует возможность прогнозирования резекции НПВ по данным предоперационной визуализации у взрослых пациентов с почечно-клеточной карциномой, имеющей распространение в просвет НПВ [31]. Наличие полной окклюзии и длительной обструкции НПВ может предполагать адекватный коллатеральный кровоток и позволяет выполнить резекцию сосуда единым блоком с опухолевым тромбом без последующего восстановления естественного венозного возврата. Однако при отсутствии развитого коллатерального кровообращения пластика НПВ становится обязательной [31, 32]. 
На способах реконструкции НПВ внимание акцентировано в ограниченном числе публикаций. F.F. Marshall и B.A. Reitz рекомендуют использовать сосудистую «вставку» из аутологичных вен или ксеноперикарда [33]. Следует иметь в виду, что аутовенозные трансплантаты применимы у детей не всех возрастов, поскольку объем доступного сосудистого материала при массе тела менее 10 кг мал. Альтернативой являются различные виды синтетических протезов, однако их применение в ряде случаев осложняется тромбозом и/или инфицированием [34].

Еще одной отличительной особенностью описанного наблюдения является восстановление венозного оттока от культи печени. В отличие от пациентов с нефробластомой вопрос о реконструкции гепатико-кавального конфлюенса у пациентов с опухолями печени встает чаще $[35,36]$. В настоящем же наблюдении использован ксенографт, из которого был сформирован кондуит, проксимально анастомозированный с устьями левой и срединной печеночными венами, а дистально - с правым предсердием. Важно отметить преимущества использования коронарного аспиратора, который в ходе кардиохирургического этапа операции осуществляет дренаж крови из печени, позволяет не выключать печень из кровообращения и не осуществлять ее холодовую перфузию. У описанного нами пациента именно таким образом осуществлялся отток из устья левой и срединной печеночных вен после экстирпации культи НПВ и во время гепатико-атриальной реконструкции.

\section{ЗАКЛЮЧЕНИЕ}

Опухолевый тромбоз НПВ у детей чаще осложняет течение злокачественного процесса при опухолях почки и печени. Злокачественные эмбриональные опухоли других локализаций, распространяющиеся на НПВ, редки [2-6, 9, 37], а публикации о распространении на камеры сердца вовсе единичны. Согласно данным литературы [27], наличие опухо- левого тромба не влияет на онкологический прогноз пациента с нефробластомой, неоадъювантная химиотерапия и верно выбранная хирургическая тактика позволяют уменьшить сроки послеоперационной реабилитации, а также обеспечить радикальность хирургического вмешательства.

Удаление тромба из камер сердца в подавляющем большинстве случаев требует осуществления искусственного кровообращения, которое позволяет не выполнять консервацию печени или ее культи и временно дренировать венозный возврат в коронарный аспиратор.

В случаях преобладания в составе тромба опухолевой ткани над «кровяным» компонентом неоадъювантная химиотерапия способна сократить его объем и изменить хирургическую тактику. Однако в любом случае при наличии тромбоза необходима гепаринотерапия. Пластика НПВ необходима при отсутствии развитого коллатерального оттока крови из бассейна НПВ, а для сосудистой пластики предпочтительно использовать аутовенозные трансплантаты. При их недоступности у детей раннего возраста предпочтение может быть отдано ксенографтам или синтетическим протезам.

Приведенное собственное наблюдение наглядно демонстрирует возможность выполнения комбинированного вмешательства большого объема.

\section{ИСТОЧНИК ФИНАНСИРОВАНИЯ}

Не указан.

\section{КОНФЛИКТ ИНТЕРЕСОВ}

Авторы статьи подтвердили отсутствие консфликта интересов, о котором необходимо сообщить.

\section{ORCID}

Akhaladze D.G. ORCID: https://orcid.org/0000-0002-1387-209X

Shatalov K.V. ORCID: https://orcid.org/0000-0003-1120-9363

Arnautova I.V. ORCID: https://orcid.org/0000-0002-3204-3561

Kachanov D.Yu. ORCID: https://orcid.org/0000-0002-3704-8783

Zarginava G.G. ORCID: https://orcid.org/0000-0002-1072-8850

Merkulov N.N. ORCID: https://orcid.org/0000-0003-0404-6420

Krivonosov A.A. ORCID: https://orcid.org/0000-0002-2636-0675

Miakova N.V. ORCID: https://orcid.org/0000-0002-4779-1896

\section{Литература}

1. LaQuaglia M.J., Kim H.B., Fynn-Thompson F., Baird C., Vakili K. Resection of hepatic tumors with central venous and right atrial extension using cardiopulmonary bypass. J Pediatr Surg 2018; 30: 14-8.

2. Ohtsuka Y., Takahashi H., Ohnuma N., Tanabe M., Yoshida H., Iwai J. Detection of tumor thrombus in children using color Doppler ultrasonography. J Pediatr Surg 1997; 32 (10): 1507-10. DOI: 10.1016/ s0022-3468(97)90578-9
3. Bagatell R., Morgan E., Cosentino C., Whitesell L. Two cases of pediatric neuroblastoma with tumor thrombus in the inferior vena cava. J Pediatr Hematol Oncol 2002; 24 (5): 397-400. DOl: 10.1097/00043426-200206000-00015

4. Day D.L., Johnson R., Cohen M.D. Abdominal neuroblastoma with inferior vena caval tumor thrombus: report of three cases (one with right atrial extension). Pediatr Radiol 1991; 21 (3): 205-7. DOI: 10.1007/BF02011049
5. Kwee W.S., Hausman R., van der Harten J.J., de Waal F.C., Schreuder C.H. Neuroblastoma with a fulminant clinical course caused by tumor embolism. Eur J Pediatr 1979; 132 (1): 61-6. DOI: 10.1007/BF00443206

6. Nagda S.N., Lo S.S., Melian E., Manera R., Emami B. Unusual thoracic problems in patients with malignancies: case 1 . Neuroblastoma presenting with intracardiac tumor thrombus. J Clin Oncol 2005; 23 (12): 2856-7. DOI: 10.1200/JC0.2005.01.115 
7. Шароев Т.А., Казанцев А.П. Рак почки у детей. Материалы рабочего совещания главных детских онкологов России с симпозиумом по проблемам опухолей почек у детей. М.; 2002. С. 36-7.

8. Derom A., De Gols J., Vermassen F., Derom F. Use of the biomedicus pump in resection of renal carcinoma invading the vena cava. Eur J Surg Oncol 1994; 20 (6): 686-7.

9. Almassi G.H. Surgery for tumors with cavoatrial extension. Semin Thorac Cardiovasc Surg 2000; 12 (2): 111-8. DOI: 10.1053/ct.2000.5083

10. Ashkenazi S., Pickering L.K., Robinson L.H. Diagnosis and management of septic thrombosis of the inferior vena cava caused by Candida tropicalis Pediatr Infect Dis J 1990; 9 (6): 446-7. DOI: $10.1097 / 00006454-199006000-$ 00017

11. Demarmels F., Lüthy A.R., Hirt A., Furlan M., Lämmle B. Inferior vena cava thrombosis in a child with nephroblastoma and combined deficiency of antithrombin III and free protein S. Blut 1990; 61 (5): 295-7. DOI: $10.1007 / B F 01732880$

12. Giannoulia-Karadana A., Moschovi M. Koutsovitis P., Tolis G., Tzortzatou-Stathopoulou F. Inferior vena cava and right atrial thrombosis in children with nephroblastoma: diagnostic and therapeutic problems. J Pediatr Surg 2000; 35 (10): 1459-61. DOI: 10.1053/ jpsu.2000.16414

13. Neves R.J., Zincke H. Surgical treatment of renal cancer with vena cava extension. Br J Urol 1987; 59 (5): 390-5. DOl: 10.1111/j.1464-410x.1987.tb04832.x

14. Давыдов М.И., Матвеев В.Б. Хирургическое лечение больных раком почки c опухолевым тромбозом почечной и нижней полой вены. Онкоурология 2005; (2).

15. Ciancio G., Vaidya A., Savoie M., Soloway $M$. Management of renal cell carcinoma with level III thrombus in the inferior vena cava. J Urol 2002; 168 (4 Pt 1): 1374-7. DOI: 10.1097/01. ju.0000023441.00587.02

16. van den Heuvel-Eibrink M.M., Hol J.A., Pritchard-Jones K., van Tinteren H., Furtwängler R., Verschuur A.C., et. al. Rationale for the treatment of Wilms tumour in the UMBRELLA SIOP-RTSG 2016 protocol 2017. Nat Rev Urol 2017; 14 (12): 743-52. DOI: 10.1038/nrurol.2017.163

17. McMahon S., Carachi R. Wilms' tumor with intravascular extension: A review article. J Indian Assoc Pediatr Surg 2014; 19 (4): 195-200. DOI: 10.4103/09719261.141998

18. Anselmi G., Suárez J.A., Machado I., Moleiro F., Blanco P. Wilms' tumour propagated through the inferior vena cava into the right heart cavities. Heart 1970; 32 (4): 575-8.

19. Green D.M. The evolution of treatment for Wilms tumor. J Pediatr Surg 2013; 48 (1): 14-9. DOI: 10.1016/j.jpedsurg.2012.10.012

20. Wagget J., Koop C.E. Wilms' tumor: preoperative radiotherapy and chemotherapy in the management of massive tumors. Cancer 1970; 26 (2): 338-40. DOI: 10.1002/10970142(197008) 26:2<338::aid-cncr2820260215>3.0.co;2-z

21. Shamberger R.C., Ritchey M.L. Haase G.M., Bergemann T.L., Loechelt-Yoshioka T., Breslow N.E., et al. Intravascular extension of Wilms tumor Ann Surg 2001; 234 (1): 116-21. DOI: 10.1097/00000658-200107000-00017

22. Hadley G.P., Sheik-Gafoor M.H., Buckels N.J. The management of nephroblastoma with cavo-atrial disease at presentation: experience from a developing country. Pediatr Surg Int 2010; 26 (12): 1169-72. DOI: 10.1007/s00383010-2667-5

23. Ritchey M.L., Kelalis P.P., Haase G.M., Shochat S.J., Green D.M., D'Angio G. Preoperative therapy for intracaval and atrial extension of Wilms tumor. Cancer 1993 71 (12): 4104-10. DOI: 10.1002/10970142(19930615) 71:12<4104::aid-cncr2820711249>3.0.co;2-7

24. Loh A., Bishop M., Krasin M., Davidoff A.M., Langham M.R. Jr. Long-term physiologic and oncologic outcomes of inferior vena cava thrombosis in pediatric malignant abdominal tumors. J Pediatr Surg 2015; 50 (4): 550-5. DOI: 10.1016/j. jpedsurg.2014.11.044

25. Elayadi M., Hammad M., Sallam K. Ahmed G., Ahmed S., Ibrahim A., et al. Management and outcome of pediatric Wilms tumor with malignant inferior Vena cava thrombus: largest cohort of single-center experience. Int J Clin Oncol 2020; 25 (7): 1425-31. DOI: 10.1007/ s10147-020-01667-0

26. Morris L., Squire R., Sznajder B., van Tinteren H., Godzinski J., Powis M. Optimal neoadjuvant chemotherapy duration in Wilms tumour with intravascular thrombus: A literature review and evidence from SIOP WT 2001 trial. Pediatr Blood Cancer 2019; 66 (11): e27930. DOI: 10.1002/pbc.27930

27. Qureshi S.S., Bhagat M., Smriti V. Murli D., Baheti A., Yadav S., et al. Intravascular extension of Wilms tumor: Characteristics of tumor thrombus and their impact on outcomes. J Pediatr Urol 2020; S1477-5131 (20): 30560-X. DOI: 10.1016/j.jpurol.2020.10.003

28. Novick A.C., Kaye M.C., Cosgrove D.M., Angermeier K., Pontes J.E., Montie J.E., et al. Experience with cardiopulmonary bypass and deep hypothermic circulatory arrest in the management of retroperitoneal tumors with large vena caval thrombi. Ann Surg 1990; 212 (4): 4727. DOI: $10.1097 / 00000658-199010000-$ 00010

29. Szavay P., Luithle T., Semler O., Graf N., Fuchs J. Surgery of cavoatrial tumor thrombus in nephroblastoma: a report of the SIOP/GPOH study. Pediatr Blood Cancer 2004; 43 (1): 40-5. DOI: 10.1002/ pbc. 20056

30. Imle R., Tosev G., Behnisch W., Schenk J.P., Rauch H., Mueller A., et al. Intracardiac Extension of Wilms Tumor: A Case of a 2.5-Year-Old Girl Presenting with Upper Venous Congestion Caused by Tumor Growth into the Right Cardiac Ventricle. Case Rep Oncol 2019; 12 (1): 33-8. DOI: 10.1159/000496020

31. Psutka S.P., Boorjian S.A., Thompson R.H., Schmit G.D., Schmitz J.J., Bower T.C., et al. Clinical and radiographic predictors of the need for inferior vena cava resection during nephrectomy for patients with renal cell carcinoma and caval tumour thrombus. BJU Int 2015; 116 (3): 388-96. DOl: 10.1111/bju.13005

32. Kearney G.P., Waters W.B., Klein L.A., Richie J.P., Gittes R.F. Results of inferior vena cava resection for renal cell carcinoma. J Urol 1981; 125 (6): 769-73. DOI: 10.1016/s0022-5347(17)55199-x

33. Marshall F.F., Reitz B.A. Supradiaphragmatic renal cell carcinoma tumor thrombus: indications for vena caval reconstruction with pericardium. J Urol 1985; 133 (2): 266-8. DOI: 10.1016/s00225347(17)48912-9

34. Caldarelli G., Minervini A., Guerra M., Bonari G., Caldarelli C., Minervini R. Prosthetic replacement of the inferior vena cava and the iliofemoral vein for urologically related malignancies. BJU Int 2002; 90 (4): 368-74. DOI: 10.1046/j.1464410x.2002.02919.x

35. Шаталов К.В., Арнаутова И.В., Джиджихия К.М., Василевская И.В., Инюшкина Е.В. Случай успешного удаления у ребенка опухоли правого предсердия, произрастающей из гепатобластомы. Детские болезни сердца и сосудов 2015; (2): 30-3.

36. Kim E.F., Shatalov K.V., Filin A.V., Arnautova I.V., Galyan T.N., Tarba N.S., et al. Surgical treatment of hepatoblastoma PRETEXT/POST-TEXT III and IV. Khirurgiia (Mosk) 2017; (12): 70-4. DOI: 10.17116/ hirurgia20171270-74

37. Bauchinger S., Lackner H., Schwinger W., Sovinz P., Benesch M., Sorantin E., et al. Primary renal neuroblastoma metastasizing into liver and lungs with tumor thrombus extension into the right atrium. Klin Padiatr 2014; 226 (6-7): 369-1. DOI: $10.1055 / \mathrm{s}-0034-1375654$ 